\title{
Risk Management Assessment for Partnering Projects in the
}

\section{Malaysian Construction Industry}

\author{
Hamimah Adnan, Mohd Nidzam Rahmat and Nur Fatanah Nadiah Mazali \\ Department of Quantity Surveying \\ Faculty of Architecture, Planning and Surveying, Universiti Teknologi MARA \\ UiTM Shah Alam Selangor, Malaysia \\ Tel: +60-3-5544 4935 E-mail: hamimah689@salam.uitm.edu.my \\ Kamaruzaman Jusoff \\ Department of Forest Production, Faculty of Forestry, Universiti Putra Malaysia \\ 43400 UPM, Serdang, Selangor, Malaysia \\ Tel: +60-3-89467176Ｅ-mail: kamaruz@putra.upm.edu.my
}

The research is financed by and Universiti Teknologi MARA, Malaysia.

\begin{abstract}
The Partnering concept is not a new way of doing business. The partnering process establishes the working relationship among the parties (stakeholders) through a mutually-developed, formal strategy of commitment and communication. It attempts to create an environment where trust and teamwork prevent disputes, co-operative bonds are fostered for everyone's benefit and the completion of successful project is facilitated. The Construction industry in Malaysia is suffering constraints in the processes of construction procurement. Thus, partnering is used as an approach in procurement that could lead toward improving performance of the construction industry in Malaysia. Organizations which have used partnering for construction projects are now reporting favourable results, which include the decreased costs, quality improvement and delivery of project to programme. Partnering has reached many benefits in terms of project cost, time quality, build ability and etc. Despite the benefits in applying the partnering procurement method, there remains risks associated with this mode of construction.

From the literature review it was found that the risk management process and partnering are critical to the success of the project. A questionnaire survey was conducted on the sample in order to examine the criticality of risk factors and to identify the effectiveness of risk mitigation measures applied in partnering. The opinions and techniques of risk mitigation were gathered through.

It was found that the most critical construction partnering risk is the partner's financial resources, clients' problems and economic conditions and financial problems among one of the partner. It is hope that the risk management programme will help to reduce the risks in the construction project in Malaysia.
\end{abstract}

Keywords: Risk management, Partnering, Malaysian construction

\section{Introduction}

Partnering is an arrangement where the participants are encouraged to work more efficiently together. It involves the parties of a construction project working together in an environment of trust and openness to ensure viability of the project efficiently without conflict. Partnering is increasingly used as a procurement method since the Latham report "Construction the Team" was published (Latham, 1994). The report recommended partnering as a means of improving inter-firm relations. Partnering is one of several strategies being proposed by practitioners, academics and managers (Cook and Hancher, 1990) and draws heavily upon lessons from Japanese manufacturing. It is defined by the Reading Construction Forum (1995) as a management approach used by two or more organisations to achieve specific business objectives by maximising the effectiveness of both parties. The approach is based upon mutual objectives, an agreed method of problem resolution and active search for continuous measurable improvements".

A partnering relationship is only recommended where the management teams of all parties involved display a fundamental commitment to partnering and where companies share a common culture (Smircich, 1985). The partnering process involves allocating time to agreed objectives, establishing an open style of communication, developing a 
mechanism for problem resolution and identifying measures designed to monitor and help improve performance (CIB, 1997). The driving force behind the adoption of project partnering stems from the recognition that a win-lose conflict is expensive, and that no one gains from it. This kind of lose-lose situation and keeping at arm's length relationships among the parties in the supply chain are pervasive in the construction industry worldwide. It calls for cultural changes among the different parties, from adversarial to cooperative relationships. Bennet and Jayes (1995) defined "Partnering is a management approach used by two or more organisations to achieve specific business objectives by maximising the effectiveness of each participant's by resources. The approach is based on mutual objectives, an agreed method of problem resolution and an active search for continuous measurable improvements."

The construction industry is plagued by risk (Flanagan and Norman 1993), but often this risk is not dealt with adequately, resulting in poor performance with increased cost and time delays (Thompson and Perry 1992). Construction projects are becoming increasingly complex and dynamic in their nature and the introduction of new procurement methods means that many contractors have to rethink their approach to the way risks are treated within their projects and organizations. Risk is a function of the interaction of uncertainty and the magnitude of potential loss or gain. Risk is also increased simply by hiring a contractor to undertake work due to the inevitable loss of employee loyalty and loss of control over sub-contractor activities (Bova, 1995). Construction work involves risk due to the complex nature and uncertainties inherent in the construction process (Al-Bahar and Crandall, 1990). Procurement now represents a significant risk, possibly the most significant, faced by most organizations (Griffiths, 1992). Consequently, the construction industry faces several problems, which act as barriers of a partnering approach to procurement.

Lamming (1993) is of the opinion that the intensity of the partnership relationship and the central philosophy of commitment can lead to a high level of pressure to perform whereby partners under pressure may be encouraged to take unnecessary risks to prove their worth. Saunders (1994) and Ramsay (1996) recognize that the information of a partnership with a supplier involves considerable risk. They assert that the risk of the transfer of power from buyer to the supplier is significant in a single source relationship. They argued further, that very large buyers will be in a position to overcome this risk by being able to dedicate resources to developing new sources of supply in the event of the original supplier flexing its new power, while smaller companies will not be in a position to insure them against this type of risk. With respect to construction, Baxendale and Greaves (1997) believe that the construction firms entering partnering with sub-contractors may limit competition resulting in the remaining firms forming cartels. Harback et al. (1994) have identified five pitfalls of partnering: unfulfilled expectations, unfinished business in which some elements or process of the partnering are still in dispute, assumption that all parties involved in the partnering are willing to share personal beliefs and thoughts, one-size-fits-all approach rather than seeing partnering as being a specific to a project and conflict between internal (relationship between various departments in a company) and external (relationship with other parties) partnering. There are however some features of the construction industry which make the introduction of partnering more difficult than in other industries.

Several attempts have been made to assess the risk factors in partnering. One common method in considering the most frequent and severe risk factors is to classify them according to their sources and to use a hierarchical structure (Saaty 1980). Such classification will make it easier for the risk manager to visualize risks clearly and to deal with them in logical, systematic way. It also seems to be more practical as it represents the actual parts of the system or the organization. It is proposed that the risks factors be categorized into three main groups: (1) Internal; (2) Project-specific; and (3) External. The internal risk group represents the risks that are unique in a partnering because different organizations are involved. The risks are developed from the nature of the operation that causes conflicts within the partnering organization. The project-specific risk group refers to unexpected developments during the construction period that lead to time and cost overruns or in shortfalls in performance parameters of the completed project. A high capital outlay and a relatively long construction period would make project costs particularly susceptible to delays and cost overruns. The external risk group represents the risks that emanate from the competitive macro environment that the partnering operates in.

The objective of this paper is therefore to identify the effective risk management measures applied to mitigate the risks faced by the construction industry from the used of the partnering procurement method in Malaysian construction industry.

\section{Methodology}

A questionnaire survey was conducted based on the risks associated within partnering project and the effective risk management measures used to mitigate the risks. The objectives of the questionnaires survey were to investigate the critical factors in the partnering system in Malaysia and the most common and effective measures that industrial participants adopted for risk management. Questionnaires survey was sent to forty (40) organizations (comprising consultants, contractors and clients) involved in construction works with a cover letter explaining the aims of the research. Twenty (25) copies were duly answered and returned. A Likert scale of 1-5 was used in the questionnaire. The 
questionnaire was divided into three groups. Respondents were asked to respond to three sections, described in detail below:

\subsection{Analysis of Questionnaire}

The analysis of data presented in the subsequent section will show the questions put forth to the respondents via as the headings or sub-headings, with the analysis of the responses clearly indicated.

Part A: General information about partnering

Question in Part A: attempt to obtain information and to identify respondents' experience on the implementation of partnering systems. For this part, the authors only analyzed and explained the important questions regarding partnering in general.

1) Experience and participation in partnering

There were 25 respondents where 17 of them were Main Contractors, 4 Quantity Surveyors, 2 Clients, which were $68 \%$, $20 \%, 10 \%$ in percentage respectively. This was followed closely by Project Managers and Architects, with $4 \%$ each respectively. Respondents were asked on their involvement in the partnering project. Forty-seven percent (47\%) of the respondents claimed that the client determined the concept of partnering, while $43 \%$ of them claimed the contractors determined the concept and $10 \%$ respondents claimed that it was the design team. Clients were the leader of the project, in which, he had to formulate his own concept. The other parties were tools used to fulfill the client requirement.

2) Were there a partnering charter and how many objectives were there?

Partnering charter is a part of partnering process where all parties used it as their mission on the projects. It was found that 16 out of 25 respondents had partnering charter on their projects. About $44 \%$ of respondents had $10-15$ objectives in their charter, while the lowest was $31 \%$ with $2-5$ objectives.

3) Was there a partnering workshop?

Thirteen (13) of the 25 respondents had attended partnering workshop, which was the most important element of the partnering process. The balance of 5 respondents did not answer the question. All parties and stakeholders must attend the Partnering Workshop where the objectives of the project would be aligned and the ground rules for the Partnering arrangement would be established.

4) How many stakeholders were involved in the project?

From the survey, $48 \%$ of the respondents claimed that they had $4-6$ stakeholders in their partnering project, while $33 \%$ and $19 \%$ of the respondents claimed that they had less than 4 stakeholders and $7-12$ stakeholders in their project respectively. The number of stakeholders depended on the size of project. "Stakeholders" here refer to the parties who participated in the projects such as design team and main contractor who signed up for the partnering Charter.

5) What size of project is suitable for partnering?

Sixty-eight (68\%) of the respondents claimed projects that were worth more than Ringgit Malaysia (RM 40 Million) were the most suitable for the implementation of partnering. However, $32 \%$ claimed the suitable size was 20.0 million to 40.0 million.

6) Who should own the partnering charter?

From the survey, $56 \%$ of the respondents claimed that the main contractor should own the Partnering Charter and other $36 \%$ agreed that clients should also own the Partnering Charter. However, the partnering project practiced by the Malaysian Public Works Department required all the parties to be involved and own the charter in order to ensure the mission was achieved.

7) Who stands to benefit financially from partnering?

Forty-eight (48\%) of the respondents claimed that the main contractor stood to benefit financially from partnering while $32 \%$ said that the client should own it, in situations when the project was completed on time and there were less variation orders or extensions of time.

Part B: Risk factors associated with partnering in particular and the construction industry generally

Questions in Part B attempted to identify the risk factors that were mostly involved in partnering. The risks factors were based on the frequency of respondents who answered the questionnaire. It was analyze on group basis. The ranking of each of the risk groups was as following:

1) Partner's Financial Resources and Managerial Competence

Financial problem of a partner's parent company. It received a mean of 4.12, far higher than the rest. Another risk factor related to a partner, its lack of management competence and resourcefulness, which was ranked $5^{\text {th }}$. Thus, the 
credit-worthiness of a prospective partnering parties' parent company should be scrutinized and its current management competence and resources must be ascertained.

2) Disagreement on Profit/Loss, Accounts and Work Allocation

Another critical risk factor was the disagreement on accounting profits and losses. It was ranked as second. Other disagreements such as the allocation of the staff position and the allocation of work received a less critical score, ranking $7^{\text {th }}$ and $8^{\text {th }}$, respectively. Dispute over work allocation often happened when designs were changed and the changes were unfavorable to one of the partners.

3) Policy of Parent Companies toward Partnering

The policy of parent companies toward the partnering was very critical and this risk factor was ranked $4^{\text {th. }}$. The parent companies could influence a Partnering performance by limiting its autonomy, contributing under-qualified staff and delaying the required funds. A Partnering agreement was composed of "the terms, resources, shares and management policies". Once the policies of a parent company changed, support for the partnering be reduced and it was difficult to keep the partnering running smoothly.

4) Distrust

Distrust among Partnering staff from different partners was also a critical risk factor in Partnering. It ranked third. In a typical Partnering, both general managers and functional managers would be drawn from their parent company to balance the influences from each parent company. Each manager was given mandate to both manage the partner and look after the parent company's interests. Thus, it was not surprisingly that the working relationship between the two managers tended to be strained, cumbersome and inefficient.

5) Technology Transfer Dispute

Technology transfer dispute was the least critical factor in this group. Technology transfer was usually carried out in limited areas, through training to local staff during the design and construction phases. The companies existed mainly for commercial gain and their main objectives were more concerned with completing the project on time and budget rather than successful technology transfer.

\section{6) Client's Problems}

Client's problems in this research consisted of two main elements: (1) Its cash flow problem; and (2) Its excessive demands and variation during the project's execution. A client's cash flow problem is regarded as the most critical risk factor to Partnering. It received a value of 4.20 and was ranked first in this group among all factors considered in this research. This financial risk to the Partnering contractor included whether the owner had sufficient funds to complete the project or had the availability of funds for progress payment. Thus, a client's cash flow problem did influence the cash flow of the contractor. Excessive demands and variation ranked fifth in this group. The risk to the Partnering lay in the potential significant change of work allocation within partners, the disruption of work and associated claims.

7) Managers Unwilling to Relinquish Control

This risk was also considered the most significant which supported the view held by Gattorna and Walters (1996). If senior management refused to allow a project team to act in accordance with project goals, then this would obviously impede a successful Partnering relationship. Partnering involved TQM principles which including involvement in decision-making at all levels. If management refused to support such a culture, then benefits were likely to be reduced.

\section{8) Project Relationship}

The other most critical factor was poor project relationship which received a critical value at 3.16 and ranked the $3^{\text {rd }}$ place in the Project-specific risk group. A lack of communication and poor relationships could occur within the parties in a project. Relationship could become strained when the partner were directly to the client without informing his counterpart first.

\section{9) Sub-contractor and Suppliers}

Currently, in the construction industry, many project activities are being sub-contracted by the main contractor. These risks were uncertainties related to the sub-contractor's or suppliers technical qualifications, punctuality, reliability and financial stability (Akinci and Fisher 1998). These risks could result in time loss and increased costs during construction. This risk is rated $4^{\text {th }}$ as a critical risk factor in the group.

\section{0) Contractual Risk}

Compared with other risks, disagreement on some conditions in the contract was considered to be less critical. It was ranked last in this group. The average index was 1.68 and still quite critical. Building contracts dealt with the relationships between parties in the contract and the allocation of risks. Contractual risks were usually caused by 
disagreements arising from flawed contract documents, inappropriate types of contract, improper tendering procedure or improper contractual clauses.

11) Economic Risk

Macroeconomic conditions, which determined the overall performance of the construction industry, were critical to the performance of a Partnering. Risks of economic fluctuation and inflation were ranked $1^{\text {st }}$ and $2^{\text {nd }}$ respectively. These factors could have a substantial impact on the profit or loss of each participant in a partnership. Economic slowdown caused the construction market to shrink. The industry became more competitive and the contractor's profit margin was significantly reduced.

12) Environmental Risks

The environment has certain critical influences on a Partnering. The environmental force majeure risk could cause destruction of facilities, equipment, material and labour death. It was ranked $3^{\text {rd }}$ in this group. The pollution effect on a Partnering is considered least critical by the respondents, as it obtained a value of 1.48 .

13) Social Risk

Social risk factors include security problems, language barriers and different cultural and religions backgrounds. The survey showed that these risks were not so critical for a Partnering. The three factors are ranked $6^{\text {th }}, 7^{\text {th }}$ and $8^{\text {th }}$, respectively. These factors were considered less critical compared with other factors. This was due to the technically oriented construction professionals who used keywords and drawings common among partnering participants form different cultural and linguistic backgrounds. Thus, it was regarded as less critical.

Part C: Identification on the effective risk management measures in Partnering

A total of 28 risk management measures were listed in the questionnaire. They were assessed from a scale of $1-5$. All 28 management measures are categorized into eight (8) main groups, namely: agreement, partner selection, sub-contract, engineering contract, employment, good relationship, control and others. Each group will be discussed in detail in the following sections.

The choice of the partner is critical for completion of the particular assignments. It is found that selecting a partner that is credit-worthy and financially strong are effective measures to mitigate risks in operating Partnering. These two individual measures share a similar effectiveness, which received an average index of 4.24 each. It is essential to ascertain that a prospective partner can provide sufficient financial resources to maintain the partner's effort. For example, during initial stage, a substantial infusion of cash will be needed for mobilization costs associated with the work force, including camp construction and the assembly of plant and equipment. This cash should be deposited in a Partnering bank account with an agreement that the partner can draw on the interest until the funds are actually required.

An engineering contract is the legal linkage between the client and contractor who are bound together through the allocation of risk and profit in the contract. From the survey, it is clear that the partnered contractor should negotiate for an adjustment clause in the contract, particularly a reimbursement clause to mitigate the loss from inflation or a client's demand variation during the construction period. It should request an extension of time when force majeure risks occur during the construction period; an index of 2.64. The partners should reach an agreement on staff position and ensure that an initial disagreement would no re-appear during project operation. An effective measure is to distribute positions in different work packages according to a participant companies' expertise; this measure received an index of 4.20. One effective measure to counter staff problems and to ensure a smooth daily operation is to recruit local staff with bilingual ability. It received an index of 3.60. Bilingual ability can offer better communication between partners.

The problem of distrust could exist all the way from the top management down to the operational level. The directors should ensure staff commitment, co-ordination and trust to remove this obstacle. This is done by enhancing communication quality and conflict resolution technique (Mohr and Spekman, 1994). Carefully selecting staff for the project and employing unbiased and experienced staff are effective measures to remove distrust within the Partnering staff: they both received an average index of respectively. The effective measures that can mitigate sub-contracting risk include using experienced and familiar sub-contractors and suppliers, engaging local security at the site and sub-contracting to local pollution control specialist. Approximately $80-90 \%$ of the work on a construction project is performed by sub-contractors (Millman, 1990). Therefore, it is not surprising that research showed that using experienced familiar sub-contractors and suppliers is critical. The measure received a value of ranking in $1^{\text {st }}$ place in the sub-contract measures. It is imperative for the local contracting firm to use keen judgment when selecting sub-contractors for the project (Kwok and Hampson, 1997). In rural areas, it is necessary to employ efficient security guards at the site. Using security firms is considered to be an effective policy with an index of 3.08.

Pollution at the site received greater attention this days and sub-contracting pollution control to a local specialist is seen to be an effective measure. It received an index of 3.00. The other effective measure related to sub-contracting is to 
select efficient sub-contractors who can complement the shortcoming of partner and it received an index of 2.48. Conducting detailed feasibility study of the project, insuring insurable risks policies and appointing an independent account auditor which received an index of 3.32, 3.16 and 2.60 respectively, must be adopted by Partnering. One of the cardinal operating features of a construction Partnering is that the work must go on irrespective of the conflict. If the partner is unable to agree, there should be a summary procedure for permitting the work to continue. This can be accomplished by designating a person, not necessarily an arbitrator, to whom the dispute will be referred. It can be an outsider, a respected individual or a senior management person from one of the partners who can make the decision. Nevertheless, renegotiation is very important to all the partners, even though it received an index of just 2.08.

\section{Conclusion}

In order to minimize the chances of failure or underperformance of a partnering, risk management techniques must be introduced into the construction industry. The critical risk factors must be identified before making any meaningful Partnering agreement. The critical risk factors can be systematically studied based on Internal, Project-specific and External risk groups.

Among all of the risk factors, those associated with financial, project relationships, economic conditions and sub-contractors are considered the most critical in Partnering. To mitigate the risk factors in Partnering, one must develop appropriate strategies. These include agreement of contract, partner selection, engineering contract, employment, good relationship, control, sub-contracting and others.

Managing a successful partnering is not easy. Risk analysis and risk management measures must be considered to improve the performance of Partnering. Nevertheless, Partnering offers a greater opportunity for improvement. As a result, most of those who have experienced Partnering are willing to get involved again because of the positive effects of Partnering. Partnering in a wide sense has been regarded to have the capability of improving the procurement approach of the industry.

\section{References}

Al-Bahar and Crandahl. (1990). Al-Bahar, J and Crandall, K. (1990). 'Systematic Risk Management Approach for Construction Projects', Journal of Construction Engineering and Management. Vol. 116 pp. 533-545.

Akinci B. and Fischer M. (1998). 'Factors Affecting Contractors' Risks of Overburden,' Journal of Management Engineering. Vol. 14 (1) pp. 67-76.

Bennet and Jayes. (1995). Bennet, J and Jayes, S (1995). 'Trusting the Team: The Best Practice Guide to Partnering in Construction', Centre for Strategic Studies in Construction, The University of Reading.

Bova, A.J. (1995). Managing Contractor Risk, Risk Management.

Construction Forum. (1995). 'Trusting the Team: The Best Practice Guide to Partnering in Construction,' Centre for Strategic Studies in Construction, Reading University.

Gattorna, J.L and Walters, D.W. (1996). 'Managing the Supply Chain,' Macmillan Press Limited, pp. 189-203.

Griffith (1992) Griffiths, F. (1992). 'Alliance Partnering Sourcing - A Major Tool for Strategic Procurement', Frank Griffiths Associates Limited.

Kwok, T.L and Hampson, K.D. (1997). 'Strategic Alliances Between Contractors and Subcontractors - A Tender Evaluation Criterion for the Public Work Sectors,' School of Engineering, Griffith University, Queensland.

Latham. (1994). Constructing the Team. Department of the Environment, pp. 14-85.

Millman, M. (1990).General Contracting. McGraw Hill, New York.

Mohr J and Spekman R. (1994). 'Characteristics of Partnership Success: Partnership Attributes, Communication Behavior and Conflict Resolution Techniques,' Strategic Management Journal. Vol. 15 pp. 135-152.

Perry and Hayes. (1985). Perry, J.G. and Hayes R.W. (1985). 'Risk and Its Management in Construction Projects, 'Proc. Institution of Civil Engineers, Part 1 pp. 499-521.

Thompson, P.A. and Perry, J.G. (1983). 'Engineering Construction Risks - A Guide to Project Risk Analysis and Risk Management', Thomas Telford, London.

Smircich. (1985). Smircich, L. (1985). 'Is the Concept of Culture a Paradigm for Understanding Organization and Ourselves, ' Organization Culture. 